\title{
Effects of musical expertise on the early right anterior negativity: An event-related brain potential study
}

\author{
STEFAN KOELSCH, ${ }^{\mathrm{a}, \mathrm{b}}$ BJÖRN-HELMER SCHMIDT, ${ }^{\mathrm{a}}$ AND JULIA KANSOK ${ }^{\mathrm{a}, \mathrm{c}}$ \\ ${ }^{a}$ Max Planck Institute of Cognitive Neuroscience, Leipzig, Germany \\ ${ }^{b}$ Harvard Medical School, Boston, Massachusetts, USA \\ ${ }^{\mathrm{c}}$ Institute of General Psychology, Leipzig, Germany
}

\begin{abstract}
Event-related brain potentials in response to harmonically inappropriate chords were compared for musical experts and novices. Similar to previous studies, these chords elicited an early right anterior negativity (ERAN). The amplitude of the ERAN was clearly larger for musical experts than for novices, presumably because experts had more specific musical expectancies than novices. Chords with a physically deviant timbre elicited a mismatch negativity that did not differentiate the groups, indicating that the larger ERAN in experts was not due to a general enhanced auditory sensitivity. The ERAN reflects fast and automatic neural mechanisms that process complex musical (music-syntactic) irregularities, and the present results indicate that these mechanisms can be modulated by expertise.
\end{abstract}

Descriptors: Event-related brain potentials, Electroencephalography, Early right anterior negativity, Mismatch negativity, Auditory processing, Music, Expertise, Musical syntax

The investigation of influences of experience on auditory information processing has become an important tool for brain research. Numerous studies have taken advantage of long-term training experience in order to study cortical plasticity (Kujala, Alho, Paavilainen, Summala, \& Näätänen, 1992; Kujala et al., 1997; Röder et al., 1999), primary auditory cognitive functions (Pantev et al., 1998), and auditory sensory memory mechanisms (Koelsch, Schröger, \& Tervaniemi, 1999; Näätänen et al., 1997). Whether the fast and automatic processing of highly complex, regularity-based auditory information can be modified by long-term training has remained unclear. To clarify this issue, the present study aimed at investigating influences of long-term experience on the processing of chords presented within a complex musical context. Eventrelated brain potentials (ERPs) to harmonically appropriate and inappropriate chords were compared for highly trained musical experts and novices.

In the present study, the term harmonic appropriateness refers to the arrangement of chord functions and to harmonic relations within a major-minor tonal context. In major-minor tonal music (e.g., "classical" Western European tonal music), the succession of chord functions and harmonic relations follows complex regularities that are described by music theory and have been denoted as part of a musical syntax (Bharucha \& Krumhansl, 1983; Bharucha

The work was supported by the German Academic Exchange Service (DAAD) and by the Leibniz Science Prize awarded to A. D. Friederici by the German Research Foundation.

Examples of the stimuli are available at http://www.stefan-koelsch.de.

Address reprint requests to: Stefan Koelsch, Harvard Medical School, BIDMC, Neurology, Dana 779, 330 Brookline Ave., Boston, MA 02245, USA. E-mail: mail@stefan-koelsch.de.
\& Stoeckig, 1987; Krumhansl \& Kessler, 1982; Maess, Koelsch, Gunter \& Friederici, 2001; Patel, Gibson, Ratner, Besson, \& Holbomb, 1998; Swain, 1997). The term musical syntax does not imply that it is a linguistic syntax in musical terms, rather it points to the fact that music is structured according to complex regularities (a feature reminiscent of language). The ability of listeners to expect specific musical events according to complex musical regularities (e.g., to expect a tonic chord at the end of a chord sequence) and to detect violations of harmonic expectancies within a musical sequence has been taken as a reflection of musicsyntactic processing (Bharucha \& Krumhans1, 1983; Bharucha \& Stoeckig, 1987; Bigand, Madurell, Tillmann, \& Pineau, 1999; Krumhansl, \& Kessler, 1982; Maess et al., 2001; Patel et al., 1998; Swain, 1997; Tillmann, Bharucha, \& Bigand, 2000; Tillmann, Bigand, \& Pineau, 1998).

The processing of musical syntax has in some recent studies been shown to be reflected in an early right anterior negativity (ERAN) that is maximal around $200 \mathrm{~ms}$ following stimulus onset in the ERP (Koelsch, Gunter, Friederici, \& Schröger, 2000). The ERAN can be elicited preattentively (Koelsch, Schröger, \& Gunter, 2002), is specifically sensitive to the violation of musical regularities (Koelsch et al., 2001), and appears to have major contributions from the inferior fronto-lateral cortex (Maess et al., 2001). Usually, the ERAN is followed by a late negativity (maximal around 500-550 ms), the N5, which is taken to reflect processes of musical integration (Koelsch, Gunter, et al., 2000; Koelsch et al., 2002).

Participants in these studies (Koelsch, Gunter, et al., 2000; Koelsch et al., 2001, 2002; Maess et al., 2001) were "nonmusicians" without any special formal musical training. The present study investigated the same phenomena in musical experts. As in 
recent studies from our group, chord sequences were presented, each sequence consisting of five chords (Figure 1a), one sequence directly following the other (Figure 1c). Sequences consisted mainly of in-key chords and were composed in a way that a musical context was built up toward the end of each sequence. Infrequently, the chord at the third $(p=0.25)$ or at the fifth position $(p=0.25)$ was a Neapolitan chord (Figure 1b). A Neapolitan chord is a subdominant variation (a minor subdominant with a minor sixth instead of a fifth). Because, from a music-theoretical perspective, a subdominant is appropriate at the third position of the chord sequence, a Neapolitan is also fairly suitable at that position. Because only a tonic chord (that is, the basic triad of the key of the sequence) is appropriate at the end of the sequence, a Neapolitan presented at the fifth position of a sequence (i.e., at the end of a deceptive cadence) is music-syntactically inappropriate (Koelsch, Gunter, et al., 2000; Koelsch, Maess, \& Friederici, 2000; Koelsch et al., 2001, 2002; Maess et al., 2001). Thus, Neapolitans at the fifth position violate the musical syntax to a higher degree than at the third position of a sequence.

Notably, there is another reason why Neapolitan chords violate musical syntax more at the fifth than at the third position: Compared to in-key chords, Neapolitan chords are in music-theoretical terms more distant from the tonal center and therefore perceived as unexpected (Bharucha \& Krumhans1, 1983; Bharucha \& Stoeckig, 1987; Krumhansl \& Kessler, 1982). Because in the present experiment the musical context was established to a high degree at the
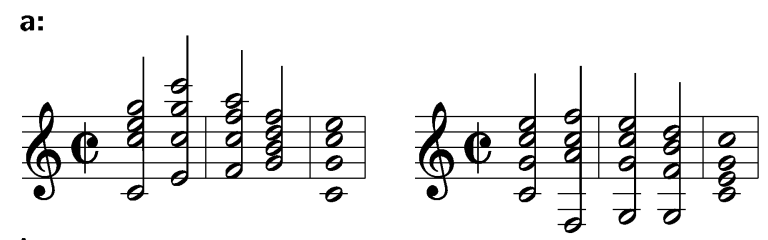

b:
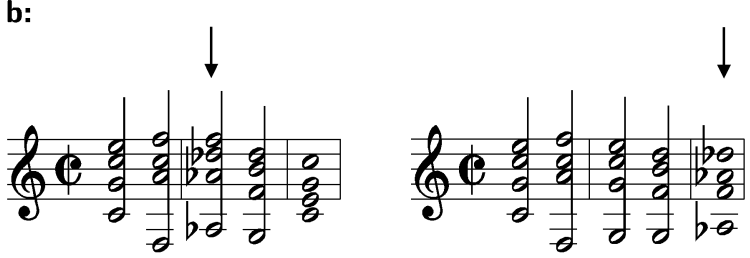

C:

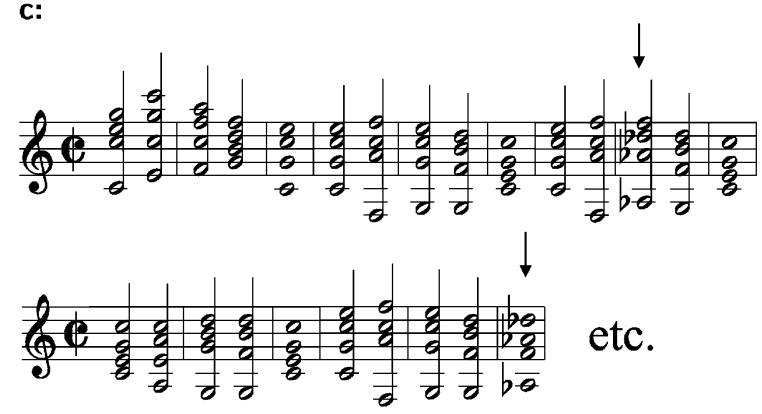

Figure 1. Examples of stimuli (the pool of stimuli used in the experiment consisted of 172 different sequences). a: Chord sequences exclusively consisting of in-key chords. b: Sequences containing a Neapolitan chord at the third (left) and fifth (right) positions (Neapolitans are indicated by the arrows). Each Neapolitan chord presented at the third position was also presented at the fifth position. During the experiment, chord sequences were presented in direct succession (c). end of a sequence (resulting in a specific notion of the established tonal key and a strong expectancy for the tonic chord), Neapolitans were less related to (and thus less expected in) the preceding context at the fifth than at the third position.

It should be noted that a Neapolitan chord itself is a consonant major chord; it is only the surrounding harmonic context that modulates the degree of music-syntactic (in) appropriateness. The degree of music-syntactic violation is reflected in an amplitude modulation of the ERAN: Neapolitans at the fifth position elicit a larger ERAN than do Neapolitans presented at the third position. This difference in the degree of music-syntactic violation is also reflected in behavioral discrimination performance: When participants are instructed to detect Neapolitan chords, hit rates are higher (around 80\%) for Neapolitans at the fifth than for Neapolitans at the third (around 60\%) position (Experiment 3 from Koelsch, Gunter, et al., 2000).

Because musical experts have more specific representations of musical regularities and harmonic relations (Bharucha, 1984), the ERAN (reflecting violations of musical regularities) was expected to be larger in musical experts than in novices. That is, a difference of the ERAN between these two groups would indicate an effect of expertise on the neural mechanisms underlying the generation of the ERAN.

\section{Methods}

\section{Participants}

Thirty-six individuals (18 musical experts and 18 musical novices, 9 women in each group) participated in the experiment. Experts were 20 to 31 years old (mean 23.6), novices 19 to 31 years old (mean 24.3). Experts had studied either musicology or an instrument at a conservatory (piano, violin, viola, cello, flute, singing); all experts received training in the theory of harmony and in counterpoint during their studies. Experts had received at least 10 years of instrumental training. Novices had never learned an instrument or singing, and they did not have any special musical education besides normal school education. All participants were right-handed and reported to have normal hearing.

\section{Stimuli}

The experimental protocol was identical to Experiment 1 of Koelsch, Gunter, et al. (2000). One hundred seventy two different chord sequences were composed according to the classical rules of harmony (Hindemith, 1940). Each sequence consisted of five chords. The first chord was always the tonic of the following cadence. Chords at the second position were tonic, mediant, submediant, subdominant, dominant to the dominant, secondary dominant to mediant, secondary dominant to submediant, or secondary dominant to supertonic. Chords at the third position were subdominant, dominant, dominant six-four, or Neapolitan sixth chord, and at the fourth position dominant seventh. Chords at the fifth position were tonic or Neapolitan sixth. Neapolitan chords at the third position never followed a secondary dominant. Neapolitan chords at the fifth position never followed a Neapolitan chord at the third position. Sequences were composed with different melodic outlines (e.g., beginning with the root, the third, or the fifth in the top voice). Secondary dominants, Neapolitan chords at the third position, and Neapolitan chords at the fifth position of the cadence occurred with a probability of $25 \%$ (resulting in a total number of 50 Neapolitans at the third and 50 Neapolitans at the fifth position). Effects of secondary dominants will not be discussed in this paper. Each variation of a Neapolitan chord was presented at the 
third position in one cadence and at the fifth position in another. Presentation time of chords 1 to 4 was $600 \mathrm{~ms}$ and of chord 5 1,200 ms. All chords had the same decay of loudness, that is, Neapolitan chords at the third and at the fifth positions were on average physically identical within the first $600 \mathrm{~ms}$. Chords were presented via speakers and played under computerized control via MIDI on a synthesizer at approximately $60 \mathrm{~dB}$ SPL. In $10 \%$ of the cadences, an in-key chord at the second, third, fourth, or fifth position was played by an instrument other than piano (e.g., harpsichord, celesta, marimba). Cadences were played immediately one after the other, sounding like a musical piece.

\section{Procedure}

Participants were instructed to look at a fixation cross. They were informed only about the deviant instruments (not about the Neapolitan chords or their nature), instructed to ignore the harmonies, and to count the deviant instruments. Participants were informed that they would be asked approximately every 2 min about the number of deviant instruments and to report their answer by pressing a response button. From the pool of 172 sequences, 200 sequences were chosen and presented in the experiment (i.e., 144 sequences of the 172 sequences occurred once, and 28 sequences were presented twice during the experiment). The duration of the experimental session was approximately $13 \mathrm{~min}$.

\section{Recording and Analysis}

The EEG was recorded from 26 electrodes of the 10-20 system, referenced to the left mastoid (sampling rate $250 \mathrm{~Hz}$ ). Artifacts caused by drifts or body movements were eliminated by rejecting data whenever the standard deviation within a sliding window of $600 \mathrm{~ms}$ or $200 \mathrm{~ms}$ exceeded $25 \mu \mathrm{V}$ at any electrode. Eye artifacts were rejected whenever the standard deviation within a sliding window of $200 \mathrm{~ms}$ exceeded $35 \mu \mathrm{V}$ in vertical or $20 \mu \mathrm{V}$ in horizontal EOG. A 200-ms prestimulus baseline was used.

ERPs were analyzed statistically by repeated-measures ANOVAs as univariate tests of hypotheses for within-subjects effects. Scores for two anterior regions of interest (ROIs) were computed: left frontal electrodes (F7, F3, FT7, FC3) and right frontal electrodes (F4, F8, FC4, FT8). Global ANOVAs were conducted with factors chord (in-key, Neapolitan), position (third, fifth), hemisphere (left, right), and group (experts, novices). The ERAN at the fifth position was statistically analyzed using a scoring window of 150 to $200 \mathrm{~ms}$. Because the ERAN has a slightly longer latency when elicited at the third position, a 200-250-ms window was used for the analysis of the ERAN elicited at the third position. The N5 was analyzed using a window from 450 to $600 \mathrm{~ms}$. The scoring epochs used for statistical analysis correspond to epochs used in previous studies (Koelsch, Gunter, et al., 2000; Koelsch et al., 2001, 2002). Only data within $600 \mathrm{~ms}$ after the onset of a chord, that is, within the presentation time of a chord, were evaluated. Hence, the acoustical input that evoked the statistically evaluated ERPs of the Neapolitans was identical for chords at the third and fifth positions (cf. Koelsch et al., 2002). For presentation purposes only, ERPs were low-pass filtered after statistical evaluation $(10 \mathrm{~Hz}, 41$ points, FIR).

\section{Results}

Brain electric responses to in-key and Neapolitan chords are shown in Figures 2 and 3. A distinct ERAN was elicited in both musical experts and novices when a Neapolitan chord was presented at the fifth position of a sequence (maximal around $200 \mathrm{~ms}$; left of
Figure 2 and top of Figure 3). This effect was considerably smaller and had a slightly longer latency when elicited at the third position (maximal around 200-250 ms; right of Figure 2 and bottom of Figure 3). The ERAN was larger in musical experts than in novices (best seen in the difference waves, Figure 2c).

A global ANOVA with factors chord (in-key, Neapolitan), position (third, fifth), hemisphere (left, right) and group (experts, novices) for the early epochs (150-200 ms for chords at the fifth position and 200-250 $\mathrm{ms}$ for chords at the third position) revealed an effect of chord, $F(1,34)=68.13, p<.0001$, indicating a larger response to Neapolitans than to in-key chords. An interaction of chord and position, $F(1,34)=26.18, p<.0001$, indicated that the ERAN was larger at the fifth than at the third position. An interaction of chord and hemisphere, $F(1,34)=11.89, p<.002$, indicated right-hemisphere predominance of the ERAN. An interaction of chord and group, $F(1,34)=4.46, p<.05$, reflected a larger ERAN in experts than in novices. An analogous ANOVA without the factor position, conducted for chords at the third and fifth positions separately, yielded chord effects for both positions (third position: $p<.02$, fifth position: $p<.0001$ ).

Neapolitans also elicited an N5 that was clearly larger for the fifth than the third position. In contrast to the ERAN, the N5 was not lateralized and did not differ by groups. A global ANOVA with factors chord (in-key, Neapolitan), position (third, fifth), hemisphere (left, right), and group (experts, novices) for the late scoring period $(450-600 \mathrm{~ms})$ revealed only an effect of chord, $F(1,34)=$ $58.48, p<.0001$, and an interaction between chord and position, $F(1,34)=18.00, p<.0002$. The analogous ANOVA without the factor position, conducted for chords at the third and fifth positions separately, yielded chord effects for both positions (third position: $p<.05$, fifth position: $p<.0001$ ). No two-way interactions were obtained. Paired $t$ tests for the same time intervals (early and late) comparing the ERPs of in-key chords for experts and novices revealed no difference between groups.

Deviant instruments elicited a large negativity with a maximum around $200 \mathrm{~ms}$, followed by a large P3. Neither of these components differed as a function of group (see difference waves in Figure 4). Although the P3 tended to be larger in experts than in novices, this difference was not significant. A global ANOVA, replacing the factor chord with factor instrument (piano, deviant instrument) for the 150-200-ms scoring window revealed an effect of instrument, $F(1,34)=19.13, p<.0001$, and no interaction between factors instrument and group, $p>.99$; the analogous ANOVA for 350 to $410 \mathrm{~ms}$ revealed an effect of instrument, $p<$ .0001 , but no interaction between factors instrument and group, $p>.17$.

\section{Discussion}

The music-syntactically inappropriate Neapolitan chords elicited an ERAN that had a larger amplitude in musical experts than in novices. This amplitude difference is most likely due to more specific representations of music-syntactic regularities in musicians (musicians have explicit knowledge about the theory of harmony, and more specific representations of harmonic relatedness; e.g., Bharucha, 1984). The ERAN is an ERP component that is elicited by violations of complex musical regularities (Koelsch, Gunter, et al., 2000; Koelsch et al., 2001, 2002; Maess et al., 2001), and the more specific representations of these regularities in experts led to a higher degree of violation in this group. It has already been shown that the ERAN increases in amplitude with increasing degree of violation (Koelsch, Gunter, et al., 2000). 


\section{a: Experts}

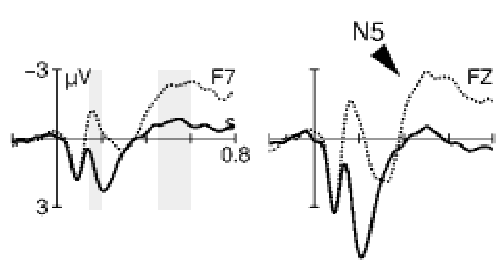

$5^{\text {th }}$ Position

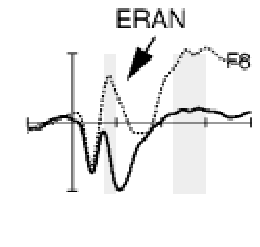

$3^{\text {rd }}$ Position

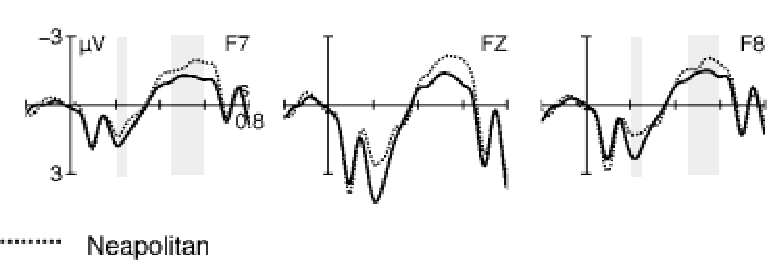

b: Novices

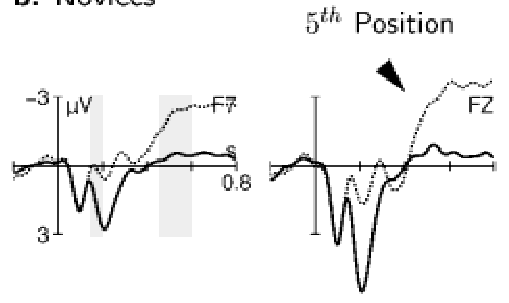

In-Key

Neapolitan

c: Difference-Waves

$5^{\text {th }}$ Position

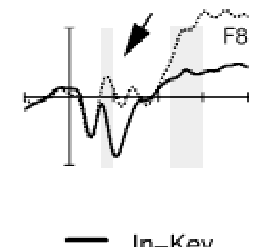

$3^{\text {rd }}$ Position

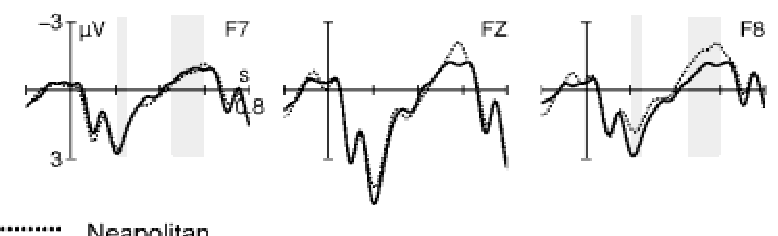

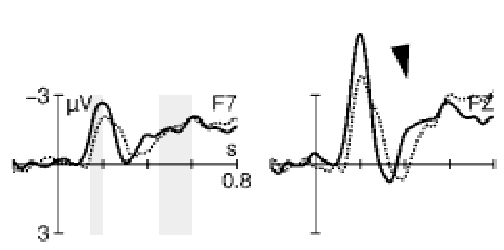

$3^{\text {rd }}$ Position

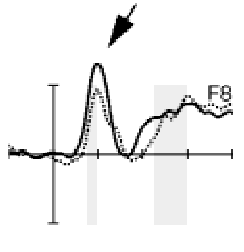

Experts

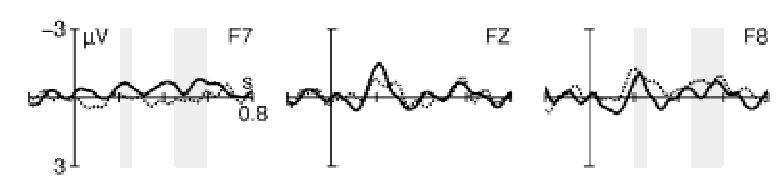

Novices

Figure 2. ERPs elicited at the fifth (left panel) and third positions (right panel) of the chord sequences. The top row (a) shows the ERPs of experts (solid line: in-key chords, dotted line: Neapolitans), and the middle row (b) shows the ERPs of novices (line-type as in a). The bottom row (c) shows the difference waves (in-key subtracted from Neapolitan chords), that is, the effects of Neapolitan chords, separately for experts (solid line) and novices (dotted line, note that the line-typed legend is different from that of a and b). ERPs were recorded from a left anterior (F7), a frontal midline (FZ), and a right anterior electrode (F8). Long arrows indicate the ERAN, short arrows the N5. Gray-shaded areas indicate the time windows for which statistical analyses were conducted. Neapolitans elicited an ERAN and an N5 in both experts (a) and novices (b). Both components were considerably larger at the fifth position (left panel) than at the third position (right panel). Importantly, the ERAN was larger in experts compared to novices (best to be seen in the difference waves of c).

All experts participating in the present study received several years of music-theoretical training, suggesting that musical experts acquire their superior processing of musical syntax during their long-term training (rather than the more specific representations of musical regularities being innate). Because the ERAN has been reported to be generated in Broca's area and its right hemispheric homologue (Maess et al., 2001), the enhanced amplitude of the ERAN might indicate a stronger activation of these areas by music-syntactic violations in musical experts.

Importantly, the amplitude of the early effect elicited by the deviant instruments (around $200 \mathrm{~ms}$ ) did not differ by group. This effect is most likely primarily a mismatch negativity (MMN; see Näätänen, 1992; Schröger, 1998) elicited by the deviant timbre of the deviant instruments (Koelsch, Gunter, et al., 2000; Tervaniemi, Winkler, \& Näätänen, 1997), with additional contributions of N1 refractoriness effects (Näätänen, 1992). The finding that the ERAN, but not the timbre-based MMN, differentiated the two groups indicates that the larger amplitude of the ERAN in experts is not due to an enhanced general auditory sensitivity (or an enhanced sensitivity for auditory irregularities) but rather to more elaborated music-syntactic processing.

Previous findings indicate that the ERAN is not an enhanced N1 (Koelsch, Gunter, et al., 2000; Koelsch et al., 2001). Moreover, the ERAN has some properties different from those of the "classical" frequency MMN and the abstract-feature MMN (Koelsch \& Mulder, 2002; Koelsch et al., 2001; Maess et al., 2001). For example, when a frequency or abstract-feature MMN is elicited in an oddball paradigm with timing identical to that of the present study, the MMN amplitude does not differ between third and fifth positions (Koelsch et al., 2001), indicating that the amplitude of the ERAN is modulated according to complex musical regularities. That is, harmonically "deviant" events eliciting an ERAN can only be recognized as deviant with reference to a fairly complex system of musical (music-syntactic) regularities. Note, however, that the 

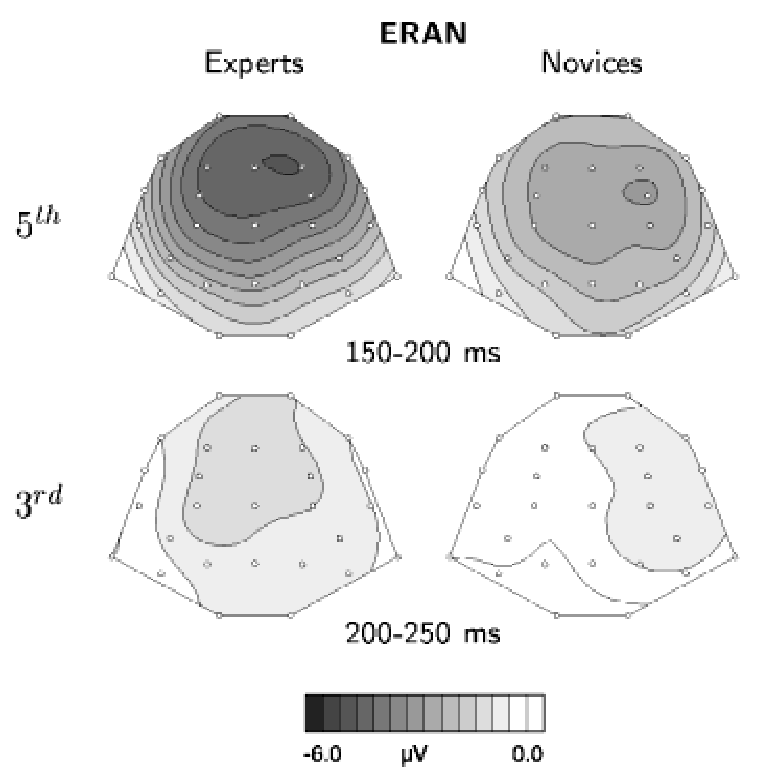

Figure 3. Potential maps (view from top, anterior is upwards) of the ERAN (difference ERPs: in-key subtracted from Neapolitan chords), separately for experts (left panel) and novices (right panel). Maps were interpolated over a time window from 150 to $200 \mathrm{~ms}$ for chords at the fifth position (upper row) and from 200 to $250 \mathrm{~ms}$ at the third position (bottom row). Gray areas indicate negative potentials.

ERAN also shares many important features with the MMN: both (a) have the same polarity (and invert polarity at mastoid electrodes when nose reference is used; Koelsch et al., 2001, 2002), (b) increase in amplitude with increasing degree of violation (Koelsch, Gunter, et al., 2000), (c) can be elicited preattentively (Koelsch et al., 2001), (d) are connected to behavioral discrimination performance (Koelsch, Gunter, et al., 2000), (e) are elicited by stimuli that do not match with a previously presented group of events, (f) can be modulated by long-term training (Koelsch et al., 1999; Näätänen et al., 1997), and (g) are generated in the peri-sylvian cortex (Maess et al., 2001). Because of the similarities between ERAN and MMN, and because the expectancies that underlie the generation of the ERAN refer to complex musical regularities, the ERAN might best be understood as a music-syntactic MMN.

It is interesting to note that the ERAN is also reminiscent of the early left anterior negativity (ELAN; Friederici, 1998, 2002; Hahne $\&$ Friederici, 1999) that has been observed in response to words

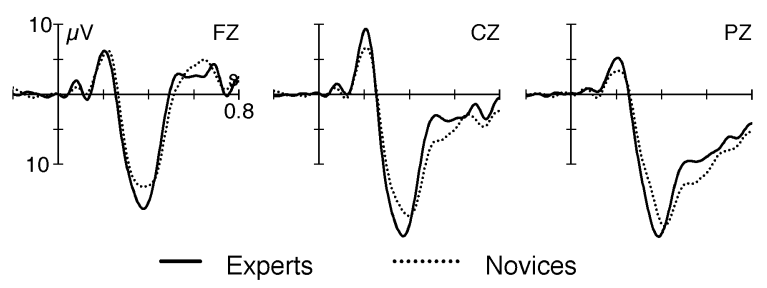

Figure 4. ERPs of deviant instruments (difference waves: chords played on a piano subtracted from chords played by deviant instruments; scaling differs from Figure 2), recorded at midline electrodes. Effects did not differ between experts and novices. with unexpected syntactic properties in sentences (phrase structure violations). That is, both ERAN and ELAN are sensitive to violations of an expected structure. Moreover, both ERAN and ELAN are negativities that are maximal around $200 \mathrm{~ms}$, have a lateralized anterior scalp distribution, reflect fairly automatic processes (Koelsch et al., 2002), and receive contributions from generators located in Broca's area and its right hemisphere homologue (Friederici, Wang, Hermann, Maess, \& Oertel, 2000; Maess et al., 2001; the ELAN receives additional contributions from the planum polare, see Friederici et al., 2000). Because of the similarities between ERAN and ELAN, it has been hypothesized that syntactic information of both music and language is processed by similar brain mechanisms (Koelsch, Gunter, et al., 2000; Maess et al., 2001). With respect to the similarities between ERAN, ELAN, and MMN, it has previously been suggested that these ERP effects belong to a family of peri-sylvian negativities that mediate the processing of irregularities of auditory input (Koelsch et al., 2001) and that the neural generators of ELAN, ERAN, and MMN are part of a highly adaptive, peri-sylvian system of auditory information-processing that mediates the processing of single tones (Näätänen, 1992; Schröger, 1998), acoustic patterns (Schröger, 1994), phonemes (Näätänen et al., 1997), tonal music (Koelsch, Gunter, et al., 2000), and speech (Friederici, 1998).

Notably, the ELAN elicited in experiments investigating natural language processing has been shown to depend on long-term experience: in contrast to native speakers, no ELAN is present in second-language learners (Hahne, 2001; Hahne, \& Friederici, 2001; for short-term effects on the ELAN when learning a miniature artificial language, see Friederici, Steinhauer, \& Pfeifer, 2002). That is, fast and automatic processing of syntax in natural language (as reflected in the ELAN) has been found to be established by long-term experience with specific language input, similar to the modulation of the ERAN by long-term training in the musical domain as demonstrated in the present study.

It is also worth mentioning that the ERAN cannot merely be due to a greater sensory dissonance of the Neapolitan chords, that is, due to the fact that the Neapolitans shared fewer component tones (or overtones) with the preceding chords than with the expected tonic chords (Parncutt, 1989; Schmuckler, 1989): in both experts and novices, the ERAN was larger at the fifth than at the third position of the chord sequence. The degree of sensory dissonance of the Neapolitan chords compared to preceding in-key chords was well balanced between the third and the fifth positions. Thus, the amplitude difference of the ERAN (between positions 3 and 5) was not dependent on the degree of sensory dissonance. Instead, the amplitude of the ERAN (and, thus, the neural mechanism underlying the generation of the ERAN) was mainly dependent on the degree of harmonic appropriateness of Neapolitans, which varied between the different positions at which the Neapolitans were presented.

The ERAN was followed by a late, more bilaterally distributed frontal negativity, the N5 (Koelsch, Gunter, et al., 2000) that did not differentiate the groups. It has been suggested that the N5 reflects processes of harmonic integration (Koelsch, Gunter, et al., 2000), similar to the N400, which reflects processes of semantic integration during the perception of language (Friederici, 1998). The notion that the N5 reflects processes different from those reflected in the ERAN is supported by the finding that the ERAN is lateralized, in contrast to the N5, which usually has a more bilateral distribution (for further differences see Koelsch et al., 2002). 
Other studies investigating effects of formal long-term musical training with stimuli that violated harmonic expectancies within a musical context were conducted by Besson and Faïta (1995) and Regnault, Bigand, and Besson (2001). Besson and Faita employed melodies, and Regnault et al. employed chords as stimuli. Other studies investigating the violation of harmonic expectancies using chords as stimuli (but only with musicians as subjects) were conducted by Janata (1995), Hantz, Kreilick, Kananen, and Swartz (1997), and Patel et al. (1998). In all these studies, positive potentials in the 300-800-ms range were elicited in response to musical expectancies; these potentials were denoted as P3, LPC (late positive component), or P600.

With respect to effects of musical expertise, Regnault et al. (2001) reported that ERPs of dissonant chords (compared to those of consonant chords) elicit an LPC (between 300 and $800 \mathrm{~ms}$ ) in both musicians and nonmusicians, the LPC being larger in musicians. Effects of subtle harmonic expectancy violations were reflected in a P3 (between 200 and $300 \mathrm{~ms}$ ) that did not differ by group. Besson and Faita (1995) also reported that LPCs as responses to harmonically inappropriate endings (but not to rhythmically incongruent endings) were larger for musicians than for nonmusicians, taken to reflect a higher degree of familiarity with tonal rules in musicians. However, the LPC appears to reflect, at least partly, decision-related processes, because the musical stimuli in the mentioned studies (Besson \& Faita, 1995; Hantz et al., 1997; Janata, 1995; Patel et al., 1998; Regnault et al., 2001) were task relevant (they required either overt or covert responses). Thus, it remains to be specified whether and how the LPC is functionally different from the P3 (Regnault et al., 2001).

However, it is interesting to note that in the study by Patel et al. (1998), in which music and language processing were compared directly, linguistic and musical structural incongruities elicited the same P600 (or LPC). Patel et al. suggested that the P600 probably reflects general knowledge-based structural integration processes during the perception of rule-governed sequences. Moreover, in that study, the harmonically inappropriate chords elicited an ERP effect similar to the ERAN, denoted by Patel et al. as the right anterio-temporal negativity (RATN). This component was taken to reflect the application of music-specific rules, or probably musicspecific working memory processes. In contrast to the ERAN, the RATN had a longer latency (around $350 \mathrm{~ms}$ ), was observed only over the right hemisphere, and has so far only been reported to be elicited in "musicians."

Whereas previous studies revealed long-term training effects for primary auditory cognitive functions (Pantev et al., 1998) and auditory sensory memory mechanisms (Koelsch et al., 1999; Näätänen et al., 1997), the present findings reveal that neural mechanisms of highly complex, regularity-based music processing reflected in the ERAN can be modulated by expertise. Notably, findings demonstrate that the neural processes underlying the generation of the ERAN are not only dependent on exogenous auditory information but modifiable by formal musical long-term training.

\section{REFERENCES}

Besson, M., \& Faïta, F. (1995). An event-related potential (ERP) study of musical expectancy: Comparison of musicians with nonmusicians. Journal of Experimental Psychology: Human Perception and Performance, $21,1278-1296$.

Bharucha, J. J. (1984). Anchoring effects in music: The resolution of dissonance. Cognitive Psychology, 16, 485-518.

Bharucha, J. J., \& Krumhansl, C. (1983). The representation of harmonic structure in music: Hierarchies of stability as a function of context. Cognition, 13, 63-102.

Bharucha, J. J., \& Stoeckig, K. (1987). Priming of chords: Spreading activation or overlapping frequency-spectra? Perception and Psychophysics, 41, 519-524.

Bigand, E., Madurell, F., Tillmann, B., \& Pineau, M. (1999). Effects of global structure and temporal organization on chord processing. Journal of Experimental Psychology: Human Perception and Performance, 25, 184-197.

Friederici, A. D. (1998). Language comprehension: A biological perspective. Berlin, New York: Springer.

Friederici, A. D. (2002). Towards a neural basis of auditory sentence processing. Trends in Cognitive Sciences, 6(2), 78-84.

Friederici, A. D., Steinhauer, K., \& Pfeifer, E. (2002). Brain signatures of artificial language processing: Evidence challenging the critical period hypothesis. Proceedings of the National Academy of Sciences, USA, 99, 529-534.

Friederici, A. D., Wang, Y., Hermann, C. S., Maess, B., \& Oertel, U. (2000). Localization of early syntactic processes in frontal and temporal cortical areas: A MEG study. Human Brain Mapping, 11, 1-11.

Hahne, A. (2001). What's different in second-language processing? Evidence from event-related brain potentials. Journal of Psycholinguistic Research, 30, 251-266.

Hahne, A., \& Friederici, A. D. (1999). Electrophysiological evidence for two steps in syntactic analysis: Early automatic and late controlled processes. Journal of Cognitive Neuroscience, 11, 194-205.

Hahne, A., \& Friederici, A. D. (2001). Processing a second language: Late learners' comprehension mechanisms as revealed by event-related brain potentials. Bilingua: Language and Cognition, 4, 123-141.

Hantz, E. C., Kreilick, K. G., Kananen, W. \& Swartz, K. P. (1997). Neural responses to melodic and harmonic closure: An event-related-potential study. Music Perception, 15, 69-98.
Hindemith, P. (1940). Unterweisung im Tonsatz, 1. Theoretischer Teil. Mainz: Schott.

Janata, P. (1995). ERP measures assay the degree of expectancy violation of harmonic contexts in music. Journal of Cognitive Neuroscience, 7 , 153-164.

Koelsch, S., Gunter, T. C., Friederici, A. D., \& Schröger, E. (2000). Brain indices of music processing: "Non-musicians" are musical. Journal of Cognitive Neuroscience, 12, 520-541.

Koelsch, S., Gunter, T. C., Schröger, E., Tervaniemi, M., Sammler, D., \& Friederici, A. D. (2001). Differentiating ERAN and MMN: An ERPstudy. NeuroReport, 12, 1385-1389.

Koelsch, S., Maess, B., \& Friederici, A. D. (2000). Musical syntax is processed in the area of Broca: An MEG-study. Neuroimage, 11, 56.

Koelsch, S., \& Mulder, J. (2002). Electric brain responses to inappropriate harmonies during listening to expressive music. Clinical Neurophysiology, 113, 862-869.

Koelsch, S., Schröger, E., \& Gunter, T. C. (2002). Music matters: Preattentive musicality of the human brain. Psychophysiology, 39, 1-11.

Koelsch, S., Schröger, E., \& Tervaniemi, M. (1999). Superior attentive and pre-attentive auditory processing in musicians. NeuroReport, 10, $1309-1313$.

Krumhansl, C. L., \& Kessler, E. J. (1982). Tracing the dynamic changes in perceived tonal organization in a spatial representation of musical keys. Psychological Review, 89, 334-368.

Kujala, T., Alho, K., Huotilainen, M., Ilmoniemi, R. J., Lehtokoski, A., Leinonen, A., Rinne, T., Salonen, O., Sinkkonen, J., StandertskjoldNordenstam, C. G., \& Näätänen, R. (1997). Electrophysiological evidence for cross-modal plasticity in humans with early- and late-onset blindness. Psychophysiology, 34, 213-216.

Kujala, T., Alho, K., Paavilainen, P., Summala, H., \& Näätänen, R. (1992). Neural plasticity in processing of sound location by the early blind: An event-related potential study. Electroencephalography and Clinical Neurophysiology, 84, 469-472.

Maess, B., Koelsch, S., Gunter, T. C., \& Friederici, A. D. (2001). Musical syntax is processed in the area of Broca: An MEG-study. Nature Neuroscience, 4, 540-545.

Näätänen, R. (1992). Attention and brain function. Hillsdale, NJ: Erlbaum. Näätänen, R., Lehtokoski, A., Lennes, M., Cheour, M., Huotilainen, M., Iivonen, A., Vainio, M., Alku, P., Ilmoniemi, R. J., Luuk, A., Allik, J., 
Sinkkonen, J., \& Alho, K. (1997). Language-specific phoneme representations revealed by magnetic brain responses. Nature, 385, 432-434.

Pantev, C., Oostenveld, R., Engelien, A., Ross, B., Roberts, L. E., \& Hoke, M. (1998). Increased auditory cortical representation in musicians. Nature, 392, 811-814.

Parncutt, R. (1989). Harmony. A psychoacoustical approach. Berlin: Springer.

Patel, A. D., Gibson, E., Ratner, J., Besson, M., \& Holcomb, P. J. (1998).

Processing syntactic relations in language and music: An event-related potential study. Journal of Cognitive Neuroscience, 10, 717-733.

Regnault, P., Bigand, E., \& Besson, M. (2001). Different brain mechanisms mediate sensitivity to sensory consonance and harmonic context: Evidence from auditory event-related brain potentials. Journal of Cognitive Neuroscience, 12, 241-255.

Röder, B., Teder, W., Sterr, A., Rösler, F., Hillyard, S. A., \& Neville, H. J. (1999). Improved auditory spatial tuning in blind humans. Nature, 400, $162-166$.

Schmuckler, M. (1989). Expectations in music: Investigation of melodic and harmonic processes. Music Perception, 7, 109-150.
Schröger, E. (1994). An event-related potential study on sensory representations of unfamiliar tonal patterns. Psychophysiology, 31, 175-181.

Schröger, E. (1998). Measurement and interpretation of the mismatch negativity (MMN). Behavior Research Methods, Instruments \& Computers, 30, 131-145.

Swain, J. (1997). Musical languages. New York: Norton.

Tervaniemi, M., Winkler, I., \& Näätänen, R. (1997). Pre-attentive categorization of sounds by timbre as revealed by event-related potentials. NeuroReport, 8, 2571-2574.

Tillmann, B., Bharucha, J. J., \& Bigand, E. (2000). Implicit learning of tonality: A self-organizing approach. Psychological Review, 107, 885-913.

Tillmann, B., Bigand, E., \& Pineau, M. (1998). Effects of global and local contexts on harmonic expectancy. Music Perception, 16, 99-117.

(Received April 9, 2001; ACCEPTEd March 27, 2002) 